\title{
Intellectual Property Rights and Consumer Behavior
}

\author{
Maria Markova \\ University of National and World Economy, Sofia, Bulgaria
}

Copyright $\subset 2017$ by authors, all rights reserved. Authors agree that this article remains permanently open access under the terms of the Creative Commons Attribution License 4.0 International License

\begin{abstract}
The paper "Intellectual property rights and consumer behavior" is focused on IP rights for product innovations and business indicators of the company and their influence on the consumer behavior. The objective of this paper is to reveal the business offer as a complex of IP rights and as a factor of consumer behavior into 2 main aspects: 1 . Product innovations with IP rights as a complex utility for consumer. 2. Business indicators with IP rights as an exclusive market proposition. This paper considers the matter of market characteristics of the business offer with implemented product innovations with IP rights for an invention, utility model and industrial design and the business indicators as trademarks, graphic designs, and domain names. The production and marketing of new products with obtained intellectual property rights the whole economic cycle goes through different phases: from a project of innovation to a market proposition with distinctive signs of IP protection. The implementation of IP into a business offer has the significant aim to achieve economic benefits from the implemented innovations and/or business indicators and to receive future revenues from the exclusive market proposition for the consumer. The final part of this paper is focused on the economic aspects of market characteristics of IP as a factor influencing the consumers and as a factor of the company competitiveness based on IP. To prove these conclusions in this paper are used examples of good practices of the successful companies, market studies and IP research.
\end{abstract}

Keywords Intellectual Property, Consumer Behavior, Innovation, Business Indicators K49

\section{Introduction}

Intellectual property /IP/ comprises of the results of human intellectual work in the fields of science, literature, arts /united by the term "copyright" /; technique, technology, design /united by the term "industrial property"/; breeder's achievements, biotechnology, software and many other areas developed by humans for the recent decades/ united by the term "new objects".
Intellectual property in the company comprises of the new technical, design and technological decisions, software and other solutions in the form of new or improved products and technologies. They are protected by patents for inventions, certificates for design and the breeder's achievements or under copyright protection.

Along with the innovations for the purpose of business the company creates and manages business indicators such as trademarks, geographical indications and domain names.

All of the above solutions are intellectual property of the company, which is reflected in its financial accounting documents such as company 'intangible assets'. These assets are entered in the accounts as the numerical value of the costs of creation and protection /cost of research, design, research and development activities and costs for filing an application for the protection of new decisions in the Patent Office of the Republic of Bulgaria and EU offices in the intellectual property rights.

Periodically, the value of the intangible asset "intellectual property" is evaluated and its value in the balance sheet of the company is updated. This update is in the direction of the increase since the initial cost of setting up the intangible asset "intellectual property" does not correspond to the higher market value of those assets after 3-5 years.

\section{The Focus of this Article is the B2C Buying Behavior in the Following Aspects According to the Mentioned above Directions}

\section{A. Product innovations with IP rights as a complex utility for consumer}

Intellectual property in the very beginning of its life cycle exists in the form of documents, schemes, drawings, models, prototypes of articles or description of the technology as a sequence of phases. At the next stage intellectual property becomes a project of innovation/product or technology/ whose implementation in business is accompanied by use of funds - capital, human and financial resources. The main aim here is the following: to realize economic benefits from the implemented innovation, through its transformation into 
an investment for the company into the form of an intangible asset and to receive future advantages

The point for intellectual property as an integrated utility /basic and additional / will be presented on the basis of marketing theory for consumer preferences and utility, based on the use of the categories 'basic and additional utility'.

The category 'basic utility' of a product is based on the view how to satisfy the needs of first and second level of the hierarchical pyramid of Maslow and it corresponds to the level of the functional characteristics of the expanded concept of product. The category 'additional utislity' corresponds to the satisfaction of the needs of IV-th and V-th level of the scale of the needs by Maslow, which are associated with social class and social status.

Undoubtedly, the products manufactured in a new project, model, design or other innovative solution add value to the basic utility of the product at the level 'functionality' and increase the additional utility of the product at the 'symbolism' and 'aesthetics', which is most often done through design. The user gets experience and pleasure by "possession of the product", which is attributed to a certain socio-cultural level and also increases his 'self-assessment' and this possession is a certain form of "self-realization". What is more this is most often achieved throughout user information and through image effect as a component of realized innovation or brand loyalty: the signs ' $\mathrm{P}$ '- invention, protected by a patent, ID - protected design, R-protected mark. The signed product provides a greater total utility, and therefore it increases the beneficial effects as one of the indicators of the analysis of the relationship "product competitiveness".

\section{B. Business indicators with IP rights as an exclusive market proposition}

This point of intellectual property as a business indicator /communication and image value/ will be presented in terms of the following two functions "corporate identity" and "differentiation".

Understanding the term 'identity' as a set of methods, tools and programs through which the company is presented to the public, the author of this article accepts the thesis that 'identity' is achieved mostly by the company's products and the company's communication strategy. Undoubtedly, the product as a tool of the corporate activity is focused on the implemented innovative projects, protected as inventions, utility models, designs, or other objects. The company creates its identity throughout a deliberate program that is intended to impose identity using communication means for instance - names, signs, symbols, atmosphere and events. Identity is established through the following business indicators: brands, logos, slogans and others signs protected most often - such as trademarks, designs, geographical indications or company names.

'Differentiation' is "a set of significant differences that distinguishes the firm's offers from those of the competitor's." The real or imaginary design parameters of the company's products is the grounds for distinction, qualification and these parameters make preferable certain company's products to others. Based on the fact that today the markets of consumers and producers are growing internationally and that the competitive struggle is no longer carried out on the level "quality - price", we could infer that today's competition at the market is a major factor in the field of corporate identity and company differentiation.

Especially, in terms of the digital global market, those factors are a crucial but of course standing in parallel with the company website. Nowadays, the website is the "face" of each company. The company is presented on the global market with a web access to the company's products specified for different consumers. The company's participation in social networks is imperative because of its growing importance to all users. Today consumers change their habits and in many cases, the physical act of purchasing goods and services is not realized in a real market environment but in the online digital environment.

Consumer behaviour is influenced by a range of economic, social and personally determined factors. In this article we pay attention to the following economic and social factors as: salary, income, lifestyle, personality, knowledge, and prior experience with this type of product and brand. Personally determined factors include the individual's motivation, personal values, attitudes and beliefs, type of personality /intro and extravert/, age, occupation and lifestyle.

The consumer purchasing behavior is based on the need of possession and use of goods and the specific market factor as influenced on the market and purchase decision. To understand consumer behavior, it is important to take into account the following factors: signed with patent, design label or TM goods. This understanding is based on the Hierarchy of Needs - five levels of needs, organized accordingly to their different importance. Especially we pay attention to: 'belonging'- the need and the desire for group acceptance and socialization; 'esteem' - the need for status, recognition and self-respect and 'self-actualization - the desire for self-fulfillment.

To sum up: The choice and purchase of IP rights included goods reflects additional utility and the socio-economic value of those types of goods. In addition to the better quality and attractive appearance it corresponds to meet the needs of social status, social enrollment and personal image in the society. There is a slogan: My personality/ 'my personal I' is identified with possessed and used by me goods.

Many people as a priority shop on the Internet as a market environment.

In addition, modern technologies allow to offer almost all activities online - from shopping on the internet, banking, communication, performing cultural activities, entertainment, travel, even living in different social platforms. The website of the company and the presented on it names, symbols, graphic signs shall be protected as an industrial design. Those signs are under IP protection as trademarks, graphic designs and domain names.

That's why intellectual property is a key factor in 
consumer influenced society for consumer behavior and consumer choice and also is a key factor for obtaining the economic benefits by the company. Intellectual property becomes a valuable market factor, generating and maintaining the competitiveness of the company.

\section{Conclusions}

The substantiation of this thesis - intellectual property as a product innovation and business indicators leads to good business results for the company.

Generally, obtained IP rights of the company leads to the good result called 'market advantage' under consumer preferences.

The presentation of this question will be done for the different subject-holders participating in the process of creation and implementation of IP in the company:

A. The economic benefits for the author /inventor, designer, creator/

The author of the creative result - product, technology, new software or other, will receive economic benefits in one or more of the following aspects:

- obtaining an economic benefit from the implementation of IP object as a result of the higher productivity, the higher volume and the higher market price;

- selling the patent or to license the patented invention or registered utility models or design: the owner of IP will win from the transfer of intellectual property rights / it happens when the company does not intend to introduce in the production the patented product or technology in cases that are outside of its business profile /;

- granting licenses / full, exclusive or non-exclusive / and to receive royalties or taxes from one or more licensees in parallel with the possibility to use this object of industrial property as himself in own business.

B. The economic benefits for the company that will implement the intellectual products. Business entity that innovates its own business will realize economic benefits in the following areas:

- carrying out the reduction of the cost of production and marketing - regardless of the needed investment for their implementation;

- production and realization of a greater volume of production based on innovation;

- realizing great and additional earnings from implemented and realized production

All of the above mentioned aspects are the economic nature of the objects of intellectual property. Those aspects are identified as economic benefits from the innovative companies - 'spin off companies'. They are economically motivated to implement and realize industrial property due to the known economic phenomenon "patent monopoly" and are related to a 'monopoly price' and 'monopoly profit'.

The mentioned above are united in a whole when it comes to business innovation based on intellectual property - new products and new technologies in the form of invention, utility model, industrial design, topography of integrated circuits, software and others.

C. economic benefits for the society as a whole

In practice, the existence and accumulation of intellectual property is beneficial for the whole society: there is a possibility to use patented solutions for research, academic and other scientific or personal activities during the period of IP protection. After the expiry of the term of protection of industrial property those innovations become a part of the scientific and technical and technological level of the society as a whole.

According to the honest practices within the patent attorney services realized by the author of this article there are going to be presented some examples from the Bulgarian practice, undoubtedly supporting the idea for a successful competitive strategy achieved through innovation protected as intellectual property seen in the form of investment of the company for their implementation and marketing.

Example 1: Product Innovation of "Telesat" Ltd. "Management System cable networks", developed and protected as an utility model under N BG 1936 has led to successful participation in the competition session 2007-2013 "Competitiveness" of the Ministry of economy, which has provided investment resources for its implementation. This innovation has been implemented in the company's own business cycle owner of utility model and nonexclusive license to use this innovation has been given to another company. This acting license agreement is registered under number 1293686 with the Patent Office of the Republic of Bulgaria. Thus, the company - owner of product innovation, protected by a utility model realizes the economic benefit as both use in their business and by receiving royalties from the licensee company.

Example 2: The inventor A. Gonov creates innovation "Equipment for the production of electricity from wind-driven generator" protected simultaneously as an useful model for the territory of Bulgaria under N BG 1498 2011 and as a registered Community Design for EU with N RCD 0025904552014.

At the beginning of 2015 the established by the inventor A. Gonov company has started producing electrical generators based on the innovation protected by the mentioned above IP rights with good perspective for signing a license agreement with other companies from Europe.

Example 3. The company 'GH Group' LTD specializing in the production of bio foods, increased sales in the last five years as a well-founded brand strategy: through market positioning and creation of associations in consumers' minds for the company offering pure and high quality products, using business indicators protected by CTM /TM for EC/ 'Bolkan food', by RCD /Registered Community design/ 'Oreshak handmade' and company domain name. 
The companies mentioned above can be seen as examples of good business practices in the area of product innovations and business indicators with IP rights have been achieving positive economic results in their business sphere.

\section{REFERENCES}

[1] Becker, J., Marketing Konzeption, Muenchen, 1992

[2] Markova M. "Design Management", PC "Stopanstvo", 2010

[3] Porter, M., Competitive Advantage of Nations, 'Classic and style', 2004

[4] Sullivan, Arthur, "Economics: Principles in action. Upper Saddle River, New Jersey, Prentice Hall, 2003

[5] www.bpo.bg

[6] www.espacenet@epo.org

[7] www.wipo.int 